\title{
Resistencias en la resistencia: representaciones distópicas de la esperanza en La última canción de Manuel Sendero y El ruido del tiempo*
}

Resistances in the Resistance: Dystopian Representations of Hope in La última canción de Manuel Sendero and El ruido del tiempo

\author{
Gabriel Saldías Rossel \\ University of British Columbia \\ gasaldia@gmail.com
}

El presente artículo examina el rol de la esperanza en dos novelas distópicas publicadas durante la última dictadura militar en Chile. A partir de un análisis comparado, sustentado teóricamente por propuestas del campo de los estudios utópicos, se buscará evidenciar de qué manera la representación distópica de la esperanza problematiza el binarismo resistencia/oficialismo mediante un análisis crítico de las condiciones de posibilidad de la esperanza y de las contradicciones inherentes a su configuración y manifestación política en un contexto dictatorial.

Palabras clave: Resistencia, ideología, distopía.

The present article examines the role of hope in two dystopian novels published during the last military dictatorship in Chile. Employing a comparative approach that draws on proposals from the field of utopians studies, we seek to make manifest how the dystopian representation of hope problematizes the binary opposition between officialism and resistance through a critical assessment of the conditions of possibility of hope and the inherent contradictions its configuration and political manifestation entails in a context of authoritarian dictatorship.

Keyworkds: Resistance, ideology, dystopia.

Recibido: $27 / 03 / 2018$

Aceptado: 05/03/2019

\footnotetext{
* El presente artículo forma parte del proyecto "Representaciones del imaginario social postdictatorial desde la perspectiva de la teoría utópica en la literatura chilena y argentina de ciencia ficción contemporánea (1983-2015)", número 74160006, Postdoctorado en el Extranjero de Becas Chile, CONICYT (2015-2017).
} 
Tras la general aceptación de las ideas que Ernst Bloch propusiera en su seminal texto de 1959, Das Prinzip Hoffnug, se ha vuelto un consenso el atribuir a la literatura utópica una función que se relaciona directamente con la expresión de la esperanza. La esperanza, en cuanto "emoción expectante"1 (74), como la define Bloch, constituye el motor de la "función utópica" de la humanidad (144). Esta energía primigenia, sin embargo, advierte el filósofo alemán, debe ser educada, so pena de perderse en imágenes cautivadoras y vacías, propias de los sueños nocturnos y las fantasías ilusorias. Para Bloch, el impulso utópico debe estar respaldado, tanto en forma como en función, por una docta spes o "esperanza educada" (146), es decir, una emoción expectante que se encuentre informada a partir de la experiencia material de la comunidad, de tal manera que sea capaz de impactar positivamente el desarrollo de la sociedad. Ruth Levitas sigue un planteamiento similar en The Concept of Utopia, en donde argumenta que las nuevas perspectivas teóricas en torno a William Morris y su afamada obra News from Nowhere, se desprenden, justamente, de una reconceptualización del factor de la esperanza en su trabajo: "Utopia entails not just the fictional depiction of a better society, but the assertion of a radically different set of values" (143).

Esta función pedagógica de la esperanza también se extiende sobre la literatura distópica ${ }^{2}$, que, a través de la representación hiperbólica y torcida de la sociedad, busca identificar y criticar, e incluso advertir, en torno a los elementos más problemáticos del presente. Sin embargo, la educación de la esperanza adquiere en este tipo de literatura matices específicos que exceden el binarismo positivo/negativo, ofreciendo, en cambio, una visión más compleja y problemática del alcance y potencial transformador de la emoción expectante.

En las sociedades distópicas, la esperanza constituye un enemigo formidable, pues su presencia entraña la posibilidad de cambio y de transformación futura. Por esta razón, es recurrente que uno de los objetivos más importantes de las sociedades distópicas sea acabar con la esperanza de la población. Es este rechazo explícito lo que faculta las conocidas rebeliones distópicas, en donde un protagonista, despierto a las injusticias de su sociedad, se alza contra esta para instaurar un nuevo orden ${ }^{3}$. Sin embargo, incluso en los escenarios distópicos más optimistas, la esperanza permanece en crisis, sometida a una realidad que la niega y oprime sin descanso.

Desde esta perspectiva, el presente artículo buscará examinar el problema de la representación de la esperanza en dos obras distópicas chilenas

\footnotetext{
1 Esta y todas las siguientes traducciones son mías.

2 La definición de 1994 de L.T. Sargent sigue siendo la más aceptada actualmente: "[dystopia is] a non-exiting society described in considerable detail and normally located in time and space that the author intended a contemporaneous reader to view as considerably worse that the society in which that reader lived" ("Three Faces of Utopianism Revisited" 9).

3 Al respecto, Tom Moylan ha diseñado una taxonomía que identifica diferentes tipos de distopías, dependiendo de si estas mantienen una posición "abierta" hacia el futuro (distopías épicas) o si, en cambio, ofrecen una visión en donde el futuro se ha visto por completo clausurado (distopías míticas) (Scraps of the Untainted Sky 195-196).
} 
publicadas durante la dictadura militar de 1973 a 1989. Estas obras interesan, en particular, por haber sido publicadas en un contexto que se ajusta a los parámetros de lo que María Varsam ha descrito como "distopía concreta": "Concrete dystopia designates those movements, events, institutions, and systems that embody and realize organized forces of violence and oppression" (209). Las distopías concretas, señala Varsam, sientan las bases materiales de las distopías ficcionales, ofreciendo, por lo tanto, una perspectiva única en torno a la opresión y el abuso, que excede los límites de lo testimonial para problematizar, en cambio, el horizonte de expectativas de sociedades que generalmente carecen de posibilidades de apertura y transformación. Desde este punto de vista, las distopías publicadas durante la dictadura militar representan un material idóneo para explorar los conflictos y las crisis presentes en la dimensión prospectiva del contexto autoritario chileno de las décadas de 1970 y 1980.

Dentro de este marco, la esperanza constituye un tema trascendental. Tanto en las distopías concretas como ficcionales, la esperanza se manifiesta como un componente que se encuentra prioritariamente presente en grupos que se identifican con una posición resistente al poder establecido. Sin embargo, como se comprobará a continuación, existen múltiples formas de interpretar la resistencia y diferentes formas de hacer ejercicio de la esperanza desde una posición resistente. Nos enfocaremos, por tanto, en la dimensión interna del ejercicio de la esperanza y en la conflictiva que se genera dentro de posiciones políticas resistentes que, más allá del objetivo común de sobrevivir, no logran converger en proyectos sociales afines.

A partir de esta premisa, las dos novelas que examinaremos a continuación serán La última canción de Manuel Sendero (1982), de Ariel Dorfman, y El ruido del tiempo (1987), de Claudio Jaque. Ambas constituyen distopías que se plantean la pregunta por el futuro y el espacio de la esperanza en medio de sociedades dictatoriales opresivas que problematizan cualquier noción de cambio social posible. Mediante estas narraciones será posible contemplar los límites de la esperanza como "emoción expectante" en medio de contextos distópicos en donde su potencial transformador se ve constantemente amenazado por la cruenta realidad material del día a día y la posibilidad siempre presente de que no exista un mejor mañana.

\section{1. "Docta spes" y "educación del deseo" en La última canción de Manuel Sendero}

La última canción de Manuel Sendero es la tercera novela del conocido escritor judío-argentino-chileno Ariel Dorfman, publicada en 1982 por Siglo XXI mientras este se encontraba exiliado en Estados Unidos a raíz del golpe de Estado de Augusto Pinochet. Dorfman, ferviente defensor de los ideales de la Unidad Popular de Salvador Allende y colaborador activo con su gobierno en calidad de "consultor de comunicaciones" (McClennen 15), debió huir del país tras el golpe de Estado en dirección a Argentina, para luego radicarse sucesivamente en Francia, Ámsterdam y, finalmente, Estados Unidos. Durante este período de exilio, Dorfman, más conocido en ese entonces por su trabajo ensayístico y académico, publicó tres novelas que fueron relativamente bien recibidas por la crítica internacional. 
De las tres obras publicadas desde el exilio, La última canción de Manuel Sendero fue la que más se distinguió en cuanto a calidad y complejidad, siendo calificada como "[his] most ambitious novel to date" (McClennen 133) a raíz de su compleja estructura. Temáticamente, sin embargo, la novela se ajusta al que ha sido determinado por McClennen como el eje central del proyecto estético del autor, a saber, la esperanza: "Dorfman's three exile novels [...] are marked not only by a deep sense of loss but also by persistent hope. Even as these novels describe a seemingly ubiquitous authoritarianism, they tell stories of successful although minor resistance to official history" (19).

La presencia de la esperanza en la novela de Dorfman, sin embargo, debe ser matizada. Ciertamente se trata de un tema central, pero no desde el punto de vista celebratorio que sugiere McClennen. La esperanza es puesta sobre un escrutinio poderoso, y es cuestionada a lo largo de toda la narración, sometiéndola una y otra vez a la cruda realidad del contexto autoritario en que subsiste. En otras palabras, la esperanza se ve en constante amenaza y se encuentra deslocalizada de su lugar de origen. En este sentido, es factible aseverar que la narración versa más sobre la inoperancia e impotencia de la esperanza, que sobre su potencial para transformar realmente a la sociedad y resistir la historia oficial.

El conflicto se desprende de la incapacidad de la esperanza de adquirir presencia concreta en la sociedad. Bloch ya adelantaba este problema al señalar que la esperanza, en la medida en que se ve impedida de afectar la sociedad, se frustra y se vuelve autocomplaciente. Esta es la base central del argumento con el que el filósofo alemán diferencia entre utopía concreta y utopía abstracta, desechando la segunda como mero "pensamiento ilusorio" (wishful thinking), compensatorio, cargado de "inmadurez y abstracción" (145), incapaz de representar la verdadera función utópica de la esperanza: "one which is trascendent withouth trascendence" (146). La utopía concreta, en contraste, sería anticipatoria y estaría informada por la carga transformativa de la esperanza como motor de cambio (144).

La lectura de McClennen en torno a La última canción de Manuel Sendero parece indicar que la narración construye, o al menos adelanta, una proyección que se ajustaría a los parámetros de la utopía concreta. Mi posición, en cambio, es que la novela solo presenta variedades de "imágenes ilusorias" (wishful images), cuya capacidad para efectivamente transformar el mundo se ven limitadas tanto por su alcance como por su objetivo.

Para clarificar este punto es necesario profundizar respecto de la diferencia funcional que existe entre deseo y esperanza. Como ya adelantábamos, para Bloch el principal componente que permite diferenciar entre utopías concretas y abstractas es la presencia de lo que este denomina "esperanza educada" o docta spes. La esperanza educada sería aquella que, informada por el contexto del presente, es capaz de proyectarse hacia un futuro de cambio radical:

Therefore: the act content of hope is, as a consciously illuminated, knowingly elucidated content, the positive utopian function; the historical content of hope, first represented 
in ideas, encyclopedically explored in real judgements, in human culture referred to its concrete-utopian horizon. The docta spes combine operates on this knowledge as expectant emotion in the Ratio, as Ratio in the expectant emotion (Bloch 146).

La esperanza educada produce una actitud específica, que Bloch denomina "optimismo militante" (199), capaz de movilizar al ser humano y propiciar que este abandone la actitud contemplativa y autogratificante de las imágenes meramente ilusorias de las utopías abstractas. Desde este punto de vista, las verdaderas utopías exceden la imaginación y existen, necesariamente, en el campo de la acción. En otras palabras, no se trata de hablar de cambiar el mundo, sino de cambiarlo.

La novela de Dorfman transita de manera ambigua entre estos dos polos. El protagonista de la narración, Manuel Sendero, posible referencia al cantautor chileno Víctor Jara, asesinado durante la dictadura de Pinochet, es representado como un personaje particularmente pasivo. Gran parte de la anécdota principal de la novela reposa sobre el misterio que existiría tras los sorprendentes dotes musicales del artista, capaz de movilizar a las masas e inspirar una supuesta esperanza unificadora y transformadora: "Cuando Manuel Sendero cantaba, ahí precisamente se ponían de acuerdo. Había un momento culminante en que los asistentes coreantes perdían su triste soledad de oasis y se fundían en una única profecía de voz" (Dorfman 32).

Esta impresionante habilidad para canalizar la voz popular es aquello que persigue dominar el régimen distópico de la novela, representado principalmente por "el Caballero", un personaje espectral asociado a la tecnocracia, el militarismo y el capitalismo, quien durante toda la narración acosa a Sendero y su familia para forzarlo a usar su voz en beneficio de los planes del gobierno. Frente a la presión constante del Caballero por precarizar la vida de Sendero tras su salida de la cárcel, el cantautor ejerce la resistencia a través del silencio.

Como Derrida hipotetiza en "How to Avoid Speaking: Denials", guardar silencio implica establecer una digresión basado en un secreto: "To avoid speaking, to delay the moment when one will have to say something and perhaps acknowledge, surrender, impart a secret, one amplifies the digressions" (86). Durante toda la novela, el protagonista jamás pronuncia ni una sola palabra, haciendo de su no narración una extensa y voluntaria digresión que solo aumenta la tensión entre el secreto y la presión del régimen. Sin embargo, como también advierte Derrida: "this silence yet remains a modality of speech: a memory of promise and a promise of memory" (84-85), lo que en última instancia significa que el silencio, en sí mismo, testifica el valor del conocimiento oculto y su poder. El silencio de Sendero, por tanto, constituye tanto una resistencia ante la presión del régimen como una provocación: una forma de manifestarse sin decir nada y de negarse sin decir que no.

Por esta razón es que obtener la última canción de Sendero representa el máximo objetivo del Estado distópico. La última canción es, probablemente, 
el elemento simbólico más importante de toda la novela: la imagen mítica, transmitida de generación en generación, del cantautor destruido, cantando por última vez en una noche de invierno, montado en una bicicleta en donde transporta el cuerpo inerte de su mujer e hijo (343), se convierte en una declaración poderosa que parece reafirmar el nacimiento de una utopía concreta basada en la resistencia y la lucha social. Sin embargo, nadie sabe si esto sucedió realmente.

La narración de Manuel Sendero y su hijo, apodado Senderito, se enmarca en los confines retóricos de una narración "fabulous, associated with the folk tale" (Braun 410), en donde los límites entre la verdad y la narración son muy difusos. Los hechos de la historia son relatados mediante versiones múltiples, muchas veces contradictorias, que tienden hacia el registro real maravilloso y que revelan más por lo que connotan que por lo que denotan. Estos episodios son narrados de manera oral por personajes que recuerdan los hechos a su manera, de acuerdo a sus propios intereses y posiciones ideológicas, lo que lleva a la confrontación y contradicción de las versiones, tal como advierte el Flaquísimo, mejor amigo de Manuel Sendero, quien critica las historias populares que buscan ensalzar la leyenda de "su compadre": "De aquí a poco andar todo el mundo va a estar transmitiendo el cuento. Entonces no van a ser migas, sino que balas, y después no van a ser balas, sino que mensajes o carnets falsos o lo que sea" (Dorfman 25).

Esta indeterminación factual, que se extiende a lo largo de toda la novela, sugiere que el espacio en que se desenvuelve la anécdota de los Sendero no es un territorio físico, sino discursivo. No es importante, por lo tanto, si es que los acontecimientos narrados sucedieron o no, sino que lo que importa es la narración misma. La "verdad", pareciera aseverar Dorfman desde una posición que refleja negativamente las conclusiones del "giro lingüístico" de la historiografía, depende de quién la cuente: "Los efectos -dijo ella- de eso nos acordamos. Lo demás es especulación" (Dorfman 161).

Este factor es clave, pues revela la base inestable en la que reposa la esperanza en la novela. Algunos personajes identificados con una posición resistente, como Senderito y su novia Pamela, escogen interpretar la última canción de Sendero como una muestra clara de "optimismo militante". Sin embargo, en la medida en que el "evento" solo existe como relato en la memoria, su capacidad para movilizar un cambio en el presente es limitada. En cambio, la anécdota de la última canción es convocada recurrentemente como un relato de martirio, diseñado no para modificar el estado miserable de la sociedad distópica, sino para canalizar su sufrimiento por medio de una imagen sacrificial. En otras palabras, la última canción de Manuel Sendero es un acontecimiento compensatorio, no anticipatorio; el inicio de una utopía abstracta, no concreta.

Esta incongruencia no escapa a la narración. Personajes como Eduardo y David, representantes de una resistencia más escéptica y pragmática, que rechaza las imágenes ilusorias del salvador mártir, constantemente se burlan de las versiones idealistas: "Su famosa energía no conocía límites, iah! qué motor esplendoroso era Manuel Sendero. [...]. No podemos perder, decía él, tejiendo entre cada persona y persona un manto de unidad, somos 
demasiado hermosos, somos demasiado reales. [...] Se equivocó Manuel Sendero" (Dorfman 64-65).

Esta persistente confrontación entre idealismo y pragmatismo se produce al interior de los confines de lo que Rafaella Baccolini denomina la "contranarrativa de resistencia" de la narración distópica, es decir, el espacio discursivo supuestamente unificado que se resiste a la dominación del poder hegemónico ("It's not in the Womb" 293). La contraposición, por tanto, es interna y recuerda la distinción entre los dos marxismos de Bloch, el "frío" y el "cálido", que Ruth Levitas sintetiza como "that of analysis" y "'the liberating intention' of Marxism" ("Educated Hope" 20). A diferencia de estos, sin embargo, que pueden ser reconciliados a partir de la formulación de la docta spes, la crisis de la esperanza en la narración nunca se resuelve de manera definitiva.

A pesar de representar la vertiente resistente-idealista como inmadura y compensatoria, Dorfman tampoco ve una salida en la propuesta pragmática. El principal problema de la esperanza "fría" de Eduardo y David es que es demasiado blanda, demasiado dispuesta a tranzar y ofrecer pactos y concesiones al bando opresor. El futuro, desde este punto de vista, es inalcanzable sin negociaciones que permitan seguir avanzando. La resistencia tradicional, armada y cargada de optimismo, no produce cambios empíricos, aseguran los escépticos, por lo que es necesario otro tipo de activismo, uno que permita generar cambios "desde adentro". Por esta razón es que Eduardo, originalmente un feto militante que se resiste a nacer en un país distópico, nace de todas formas, traicionando los ideales de su movimiento (66), mientras que David, excomunista exiliado por Pinochet sin posibilidad de regresar a Chile, concede una entrevista a un periódico conservador con tal de obtener una posible entrada para ver a su familia (314).

La dualidad, por tanto, siempre se resuelve de forma negativa: si se mantiene una esperanza idealista, esta degenera en ilusión, mientras que, si se persiste de manera práctica, existe el peligro de la concesión y la traición a los principios. En ambos casos la esperanza subsiste de manera amenazada, siempre en un constante estado de inestabilidad, pudiendo cambiar de golpe y sin aviso previo. Lo que se describe en la novela, en suma, no es el triunfo de la esperanza frente a la adversidad de la dictadura, sino su terrible vulnerabilidad.

A esta crisis interna de la esperanza se debe agregar la presión externa del oficialismo distópico, que a lo largo de toda la novela insiste en intentar controlar los múltiples relatos existentes gracias a la coerción política y económica. Para la lógica de la "narrativa oficial", como la denomina Rafaella Baccolini, el ejercicio del poder se desprende del control absoluto del relato histórico de la nación. Por esta razón resulta fundamental manipular a Manuel Sendero: "Que no se preocuparan por una mentira por acá o acullá, cuando estaba seguro de que el Sr. Sendero podrá colaborar en esa búsqueda del alma nacional o en planes aún más ambiciosos con talentos irremplazables. Lo fundamental era salvar esa voz para la patria, eso les dije" (Dorfman 230).

La distopía busca, en suma, controlar la esperanza popular. Debido a que esta se sostiene a partir de una educación basada en la experiencia, la 
narrativa oficial distópica procede por un camino alternativo para manipular a la población. Frente a la "esperanza educada" de Bloch, el Estado distópico ofrece una versión torcida de lo que Miguel Abensour llama la "educación del deseo": "And we enter Utopia's proper and new-found space: the education of desire. This is not the same as 'moral education' towards a given end: it is rather, to open a way to aspiration, to 'teach desire to desire, to desire better, to desire more, and above all to desire in a different way'" (Abensour 790-1). Ejemplos de esta manipulación materialista lo podemos ver en el programa de televisión al que acude Senderito para buscar al Caballero, en donde se instruye al participante a expresar un deseo "decente, razonable, un limpio deseo que juntos, unidos y sin rencor, podremos resolver" (239), es decir, un deseo que se ajuste a los parámetros del régimen.

A diferencia de la docta spes blochiana, Abensour propone que la finalidad última del pensamiento utópico es abrir el camino al deseo, pero no la determinación última de este. En este sentido, tal como clarifica Ruth Levitas: "Because the 'education of desire' eschews the prescription of a desired end, it appears to be more open, more exploratory than Bloch's 'educated hope' [...] Educated hope aims not only at an estrangement effect, but social transformation" ("Educated Hope" 24).

Esta confrontación entre esperanza y deseo se mantiene irresoluta hasta el fin de la novela. La obra de Dorfman concluye con cuatro epílogos sucesivos que explican los acontecimientos tras la muerte de Manuel Sendero. En el tercero, se reafirma la condición textual del cantautor, reducido a leyenda popular, y se constata la aparente ineficacia de su sacrificio: "A la mañana siguiente, ella se despertó, todos se despertaron, y el mundo no estaba, al parecer, alterado por la canción, la última, de Manuel Sendero" (350). Sin embargo, se sugiere un cambio, no externo, sino interno: "Les entró la sospecha, y más que la sospecha, de que el mundo podía ser cambiado, de que el mundo merecía ser cambiado, de que dependía de ellos y de cada uno de nosotros preparar un mundo en que los padres jamás tuvieran que escoger entre su dignidad y la vida de sus hijos" (352).

A pesar de la carga simbólica que este epílogo otorga a la figura de Manuel Sendero, su muerte no logra cambiar las condiciones represoras de la sociedad distópica. Los abusos del Estado continúan y la manipulación del deseo popular sigue operando cabalmente. Es cierto que se producen dos "marchas contra la muerte", en donde los fetos sin nacer se resisten a llegar a un mundo tiránico y autoritario, pero estas mismas también fracasan en su intento por transformar la realidad. El último epílogo aclara esto al señalar que Eduardo, quien durante toda la novela ha sido caracterizado como el contrario al protagonista, como un personaje escéptico, frío y pragmático, "cuidaría como si fueran suyos a los múltiples nietos de Manuel Sendero" (357).

En última instancia, se revela que el futuro será de los traidores. Los nietos de Sendero crecerán al cuidado de aquellos que pactaron su espacio en la sociedad, no de los que resistieron a la injusticia. Estos últimos permanecerán muertos, reducidos a recuerdos y a imágenes compensatorias, como las del cantautor y su hijo, que, en la medida en que forman parte del anhelo popular, no pueden evitar convertirse en residuos de la educación del deseo 
que promueven. Esta es la paradoja última de la esperanza sometida a las condiciones de una resistencia sostenida: mientras más hacia el futuro se proyecta la contranarrativa, más nostálgica se vuelve, anclando el cambio anhelado en un pasado idealista que solo existe en las leyendas populares, transformando lo que alguna vez tuvo un potencial de modificar el mundo, en una imagen ilusoria y compensatoria de sí misma, diseñada no para crear una mejor sociedad, sino para soñar despierto.

\section{Ideologización de la esperanza en EI ruido del tiempo}

Como ya hemos establecido, la amenaza de la imposición distópica en tiempos dictatoriales se desprende de su atemporalidad y rechazo al cambio. Frente a este escenario, la contranarrativa de resistencia se erige como una voz de apertura al futuro y a la esperanza de un mejor devenir: "Utopia is maintained in dystopia, traditionally a bleak, depressing genre with no space for hope in the story, only outside the story" ("The Persistence of Hope" 520).

Desde esta perspectiva, durante la distopía, la esperanza se manifiesta como confianza en que es posible superar el estancamiento, sugiriendo, implícitamente, que una vez superada la opresión esta no volverá a manifestarse. Sin embargo, no existe certeza alguna de que esto sea así, razón por la que el período posterior a la distopía es tanto o más crítico para la manifestación de la esperanza como la distopía misma.

Este es justamente el tema central de la obra El ruido del tiempo del autor chileno Claudio Jaque. Originalmente publicada en 1987 por la editorial Galinost, a dos años del término de la dictadura de Pinochet, la novela de Jaque, innovadora en muchos sentidos en un campo literario no acostumbrado aún a la experimentación de la ciencia ficción, pasó prácticamente inadvertida en el turbulento escenario del fin de la dictadura, a pesar de abordar temas muy pertinentes para la sociedad chilena de la época.

La novela de Jaque comienza describiendo un escenario familiar para la ficción distópica. Una sociedad militarizada y autoritaria, dirigida desde un misterioso búnker subterráneo, ha dividido a la sociedad en dos clases: los "productivos", habitantes de la ciudad de Coridra, espacio jerárquico y dividido en castas, y los "inactivos", que han sido concentrados en la periferia, en una ciudad desértica llamada Cinac.

Esta "ciudad ghetto" mantiene múltiples vínculos con la sociedad chilena dictatorial. Macarena Areco, por ejemplo, ha interpretado la separación entre Coridra y Cinac como una alusión a las políticas urbanas segregadoras del Chile de los años 70 (26). También podemos detectar referencias más explícitas al contexto dictatorial mediante la descripción de una primera rebelión que fue sometida violentamente por los poderes militares con ejecuciones colectivas llevadas a cabo en un estadio (Jaque 9), evidente referencia a la situación de los detenidos en el Estadio Nacional de Santiago en 1973.

A pesar de la hipervigilancia panóptica a la que se ven sometidos, los habitantes de Cinac pasan sus días resignados y aburridos, viendo televisión, teniendo sexo casual y tomando cerveza. Sometidos al ennui de una 
vida condicionada por los privilegios materiales de un Estado autoritario, el malestar social se manifiesta a través de una epifanía colectiva: "¿Podría ser la vida más que saber que uno está vivo? Emociones nunca antes sentidas emergieron. Algunos se abrazaron, como si se reconocieran después de años de separación. [...] Fue un momento único que culminó cuando Rik, con su voz profunda y resonante, gritó: iRebelión! iRebelión!" (33).

La revolución es liderada por Long y Rik, dos carismáticos líderes que proponen escapar de Cinac y acabar con el Búnker de Coridra. Más allá de este acto inicial, sin embargo, el plan posterior, especialmente en términos políticos, es confuso y ambiguo. Esta indeterminación en los objetivos a conseguir adelanta el conflicto central de la narración, que no tiene que ver con el alzamiento contra el Búnker ni el éxito de la revolución, sino con lo que sucede en el tránsito desde la militancia a la organización política.

Tras la revolución, que, en términos referenciales podemos leer como el quiebre definitivo con el Estado autoritario dictatorial, Long y Rik son separados, terminando el primero en una prisión estelar que orbita sobre la Tierra y el segundo bajo los túneles de Cinac, dirigiendo a los revolucionarios por un laberinto subterráneo en dirección al Búnker. A partir de este punto la anécdota se bifurca en dos vertientes completamente diferentes, alternando capítulos en torno a los dos protagonistas. En los capítulos dedicados a Long, se narra cómo este y sus seguidores se sublevan, por segunda vez, contra los militares al mando de la prisión y consiguen hacerse con el poder de esta, fundando una nueva sociedad. En los episodios dedicados a Rik, por otro lado, se relata, en forma de racconto, cómo el grupo de revolucionarios de Cinac consigue finalmente derrotar al Búnker y establecer un nuevo orden social basado en los principios jerárquicos de la sociedad que los antecedió.

En los más de cincuenta años en los que transcurre la novela, los dos protagonistas llevan a cabo procesos similares y paralelos que culminan en la creación de dos sociedades completamente diferentes. En otras palabras, lo que la novela de Jaque parece sugerir, superando los límites temporales de su propio contexto y contradiciendo la hipótesis de Bloch, es que no existe una necesaria correlación entre la "esperanza educada" y un mejor porvenir, proponiendo, en cambio, un punto de quiebre importante mediante la transformación del impulso utópico en ideología.

Este planteamiento resuena con la propuesta del sociólogo alemán Karl Mannheim, quien en Ideologie und Utopie describe la ideología como un "velo" de condiciones sociales que impide considerar la realidad de manera objetiva: "It refers to a sphere of errors, psychological in nature, which, unlike deliberate deception, are not intentional, but follow inevitably and unwittingly from certain causal determinants" (54). Estas "causales", especifica Mannheim, se condicen necesariamente con los factores de clase y pensamiento político. El "conocimiento erróneo" de la ideología se expresa, por tanto, en estos términos: "If erroneous knowledge was formerly checked by appeal to divine sanction [...], in which true ideas were supposedly discovered, at present the criterion of reality is found primarily in an ontology derived from political experience" (65). Desde este punto de vista, una visión ideológica de la realidad se contenta únicamente con describirla de acuerdo 
con las preconcepciones dictadas por su orientación política y de clase. Por esta razón, señala Mannheim, la ideología tiende a la autopreservación y la congruencia (78).

En contraste, la utopía, o el "estado mental utópico", constituye una orientación que es "incongruente" con el estado de la realidad en que acontece (173), por lo que busca "trascender la realidad" y romper con los límites establecidos de esta. Expresado en los términos de clase y pensamiento político previamente delineados, el sociólogo señala que: "It is always the dominant group which is in full accord with the existing order that determines what is to be regarded as utopian, while the ascendant group which is in conflict with things as they are is the one that determines what is regarded as ideological" (183).

Clave para el planteamiento de Mannheim es el hecho de que esta relación oposicional es siempre dual y relativa. No existe, como sí sucede en el planteamiento de Bloch, una predisposición a conceptualizar el pensamiento utópico como intrínsecamente "positivo" para el mejoramiento de la humanidad, sino que, en cambio, se presupone un movimiento pendular entre utopía e ideología que depende, en última instancia, del orden social establecido en un determinado momento histórico. Este relativismo conceptual incluiría la docta spes de Bloch, supuestamente formada para propiciar el mejoramiento de las condiciones sociales de la humanidad, lo que en última instancia plantea la provocadora idea de que todo aquello que en algún momento es promovido como un ideal incorruptible puede, al menos en potencia, convertirse en un nuevo sistema opresor.

Esta resulta una incongruencia particularmente relevante en un contexto de resistencia política de izquierda, así como señala Paul Ricoeur en sus Lectures on Ideology and Utopia: "After the revolution, the conservative trend plays another important role in the socialist utopia to the extent that the Party tries to preserve all its gains. When the Party is in power, it uses all the strategies of a conservative utopia" (279).

Este movimiento progresivo desde la utopía hacia la ideología, a pesar de estar prioritariamente ejemplificado en el marxismo, no es un fenómeno exclusivo a este: "He sees [Mannheim] very clearly the conservative trend of socialism, the bureaucratization of liberal utopia, the growing tolerance and skepticism, and, above all, the reduction of all utopias to ideologies" (Ricoeur 281). Mannheim intepreta este cambio como positivo y propio del mundo moderno, una condición de su realidad histórica, que contempla un gradual alejamiento de visiones "incongruentes" con la realidad, hacia una "verdadera" apreciación del mundo. Ricoeur se muestra dudoso de la conclusión del sociólogo alemán, asegurando que: "If we call ideology false consciousness of our real situation, we can imagine a society without ideology. We cannot imagine, however, a society without utopia, because this would be a society without goals" $(283)^{4}$.

\footnotetext{
4 L.T. Sargent está de acuerdo con esta premisa, pero va aún más lejos que Ricoeur, asegurando que: "Utopia is clearly of at least equal importance to ideology and, as I have argued here, probably more important" ("Ideology and Utopia: Karl Mannheim and Paul Ricoeur" 270).
} 
En la novela de Jaque, esta confrontación entre utopía e ideología se produce de manera simultánea en dos contextos diferentes. En el caso de Long, el cambio acontece una vez que este se ha liberado de sus captores en la prisión espacial en la que es retenido como prisionero y comienza a establecer un nuevo orden social. Se trata de un cambio gradual, sutil y progresivo, justificado bajo la premisa de la supervivencia en el espacio. Bajo su mando, la prisión se divide en diferentes sectores productivos, funcionando cada uno como gremios organizados en red a través de diferentes delegados. Estos, liderados por Long, quien actúa como una especie de monarca encubierto, toman todas las decisiones pertinentes a la comunidad autocrática. El experimento social, a pesar de ser espontáneo e improvisado, resulta un éxito: "A la rápida integración contribuía el hecho de que, para ese entonces, el pasado estaba cayendo en el olvido; junto a Long, una niña esperaba una hija y, en general, la comida era caliente y abundante, la fornicación había mejorado y casi no había tiempo para cumplir con todas las tareas asignadas" (167).

La vida en la prisión es, contra todo pronóstico, apacible y estable. La gente vive en paz y trabajan todos por el bienestar común. Sin embargo, el objetivo de Long sigue siendo el mismo: destruir el Búnker y permitir la liberación de Cinac. Este principio, que originalmente se manifiesta como un impulso utópico de liberación, se cristaliza en ideología en la sociedad de la prisión en cuanto se convierte en su única razón de existir, adquiriendo rasgos de aquella "falsa consciencia" que describe Mannheim. Esto queda en evidencia cuando, tras treinta y cinco años de agotador viaje interestelar, los reos descubren un nuevo planeta, muy similar a la Tierra, que ofrece todas las posibilidades de comenzar una nueva vida en un nuevo lugar, libres. Long, considerando esta nueva Tierra una amenaza potencial para su objetivo, ordena la clausura de todas las ventanas de la prisión, cerrando la esfera en una penumbra permanente y asfixiante. Su razonamiento es tajante: "Él se dirigía a la Tierra, a destruir el Búnker. No había tiempo para descansar. Bajar, incluso con la intención de permanecer solo por un momento breve, sería el fin de su viaje. ¿Quién querría regresar a la nave después de encontrar un mundo apacible? Quién sabe qué encantos permanecían escondidos bajo esa límpida atmósfera" (Jaque 183).

La posición antiutópica de Long recuerda la crítica de Eagleton en torno a la izquierda: "The problem with leftists, used to be that they were so taken up with political means that they were at some risk of forgetting or even obliterating the ends which those means were meant to serve" (38-39). En el caso de Long, esto se cumple a cabalidad y el olvido es completo, permitiendo que el medio suplante a la finalidad, concertando todo el peso de la sociedad en un solo acto revolucionario que carece de importancia. Una revolución vacía, contra nadie, para nadie; un reflejo claro de lo que Eagleton describe como la "fetichización del futuro": "If we need images of our desire, we also need to prevent these images from mesmerizing us and so standing in the way of it" (34).

Paralelamente a la anécdota del regreso de Long a la Tierra se desarrolla la historia de Rik, quien continúa con la lucha contra el Búnker tras la captura de su compañero. Inicialmente, este se muestra igualmente radical, pero tras la victoria sobre el Búnker y el fin de la revolución, Rik se vuelve un ejemplo 
claro de la "tendencia conservadora" de la ideología a la que se refieren Mannheim y Ricoeur. A pesar de declarar públicamente desear construir "la sociedad que Long habría deseado" (133), el resultado es bastante diferente.

En lugar de acabar con la sociedad creada por el régimen distópico, Rik funda la suya a partir de los principios de la anterior, manteniendo la estructura política jerárquica de la división por castas (nombrándose a sí mismo "Administrador") y aprovechando sus avances técnicos y científicos. Incluso el Búnker es mantenido, adaptado para funcionar como una suerte de museo que recuerda la memoria de los combatientes (135).

En el plazo de cuarenta y nueve años que toma a la nave de Long regresar a la Tierra, Rik crea una próspera civilización con un alto nivel científico, pacífica y libre de enfermedades. Al mismo tiempo, sin embargo, sigue siendo una civilización rígida que replica gran parte de las injusticias que la revolución buscaba subvertir. Particularmente importante en este punto es la "nueva raza" de seres creados de manera artificial con capacidades superhumanas, dueños de intelectos superiores, el poder para leer la mente y libres de todo sentimiento. Su creación lleva a un nuevo tipo de segregación, no ya de clase, sino de índole biopolítica: "Los jóvenes que te asustaron en el transporte, los Artificiales, son el comienzo de la historia. No son animales, no son el producto de un instinto, o de la administración de un instinto, como nosotros. Ellos son el resultado de nuestro conocimiento, una síntesis. Y ahora nada será como antes porque esa gente no siente nuestros miedos" (Jaque 137).

Para Rik, el auge de la nueva raza es un éxito incuestionable de una sociedad ordenada darwinianamente, en donde los más aptos dirigen y los más débiles se someten. En este sentido, se trata de un refinamiento de las políticas segregadoras del Búnker, perfeccionadas para establecer a una nueva elite en el poder, no ya militar, sino científica.

La novela concluye con el esperado reencuentro entre los dos compañeros después de casi medio siglo, haciendo patente las tensiones entre sus dos sociedades casi de inmediato. La confrontación final entre los modelos sociales opuestos queda en suspenso, ofreciendo un final abierto que resalta la ambigüedad respecto del rol de la esperanza. Este es un rasgo clave de las distopías críticas, categoría a la que pertenece la novela de Jaque: "The presence of utopian hope dos not necessarily mean a happy ending. Rather, awareness and responsibility are the condition of the critical dystopia's citizens. A sense of sadness accompanies the awareness and knowledge that the protagonist has attained" ("The Persistence of Hope" 521).

El "triste conocimiento" adquirido da cuenta de que, en un escenario como este, en donde los dos sistemas sociales creados se han vuelto rígidos e impermeables al cambio, la esperanza funciona más como un vehículo del statu quo que su contrario. En este sentido, como señala Darren Webb, es posible que la esperanza actúe de acuerdo con un paradigma conservador, que, en lugar de buscar el cambio, promueve la estabilidad. En su "epistemología de la esperanza" ("Exploring the Relationship" 199), Webb considera dos modalidades que se ajustan a la visión conservadora: la "esperanza estimativa" (estimative hope) y la "esperanza resuelta" (resolute hope) 
("Modes of Hoping" 73-75). En ambos casos, "precisely because such hopes are tapered to reality, subsequent goal pursuit will tend to reproduce this reality rather than transform it" ("Modes of Hoping" 74).

La diferencia entre los dos modos estriba en que la "esperanza estimativa" de Rik actúa en favor de la evidencia, es decir, a través de cálculos precisos respecto a cómo o de qué manera se puede obtener un objetivo final, mientras que la "esperanza resuelta" de Long, actúa contra la evidencia, asegurando que el potencial de cambio radica en el sujeto y en su voluntad única y esencial, no en el contexto. Ambos modelos son excluyentes y representan un importante cambio de la esperanza inicial, que se ajusta a la visión de Bloch, y que Webb denomina "esperanza crítica" (critical hope) ("Modes of Hoping" 71).

\section{Conclusiones}

En las dos novelas aquí abordadas, la tematización de la esperanza adquiere la forma de una dialéctica oposicional, que excede los límites referenciales de sus contextos de producción para internarse, en cambio, en la proyección futura de las contradicciones políticas representadas. Se hace complejo, por tanto, el modelo dialógico clásico de la distopía descrita en términos de "narrativa oficial y contranarrativa de resistencia", ofreciendo, en cambio, una visión en la que el conflicto se retrotrae e interioriza, adquiriendo matices ético-políticos de orden íntimo, gestados al interior de la propia contranarrativa de resistencia y el cuestionamiento de lo que significa "resistir" en primer lugar.

En el caso de Dorfman, la confrontación se produce en términos fenomenológicos, entre la posibilidad de generar una docta spes a través de la experiencia del sufrimiento y la tentación de reorientar esa esperanza hacia el campo del deseo abierto por la narrativa oficialista y el conformismo. En el caso de Jaque, por otro lado, la oposición se genera a un nivel epistemológico, a causa de la transformación progresiva del impulso utópico en ideología o, lo que es lo mismo, de una esperanza crítica, militante y abierta al cambio, a múltiples esperanzas conservadoras, concentradas en la mantención y preservación del poder político.

Los dos paradigmas, a pesar de guardar diferencias importantes que podemos atribuir a los diferentes contextos de producción de las obras -Dorfman, escribiendo desde el exilio en torno a una dictadura todavía "saludable", y Jaque, escribiendo desde Chile a pocos años del fin de esta-, se inscriben en un marco común que representa la esperanza como frágil y fragmentada. Esta diferenciación genera versiones divergentes del futuro; visiones que se oponen dialéctica y competitivamente, generando, por tanto, resistencias al interior de la resistencia, disminuyendo cada vez más su capacidad concreta de impactar la sociedad de manera efectiva.

Como advierte Ruth Levitas: "There is a fine line between abstract utopia, wishful thinking, hoping for the unattainable; and imagining, hoping for, and claiming too little, and there is no certainty that we shall draw the line in the right place" ("Pragmatism, Utopian and Anti-Utopia" 58). Ciertamente 
los límites no se encuentran establecidos de antemano y los intentos por establecer un equilibrio entre idealismo y pragmatismo tienden, generalmente, hacia uno u otro polo. Por esta razón es que los personajes de Dorfman y Jaque, a pesar de proceder del mismo núcleo de resistencia, no pueden ponerse de acuerdo en cómo crear una mejor sociedad.

La razón de esta atomización y cristalización progresiva se debe a la indeterminación inicial del impulso utópico, concentrado en la imagen ilusoria de la revolución en lugar de la sociedad que le ha de suceder, o, en palabras de Bloch, enfocado más en el aspecto abstracto de la utopía que en su dimensión concreta. Por esta razón, una vez alcanzado el objetivo inicial, la esperanza se desorganiza y desmantela, aferrándose a modelos de resistencia inoperantes en un contexto cooperativo, como el de Long y Felipe, o, en cambio, volviéndose "pragmática", cediendo espacio y generando concesiones con la narrativa oficialista, que es lo que sucede con Rik, Eduardo y David. En ambos casos, la esperanza inicial se ve eclipsada por su propia proyección, irónicamente clausurada en la realización última de su condición de posibilidad.

\section{Obras citadas}

Abensour, Miguel. William Morris: Romantic to Revolutionary. Ed. Thompson, E.P. Londres: Merlin, 1977.

Areco, Macarena. "Ciudad, espacio y ciberespacio en la ciencia ficción chilena reciente: Tres versiones del laberinto". Acta Literaria 37 (2008): 25-42.

Baccolini, Rafaella. "'It's not in the Womb the Damage is Done': The Construction of Gender, Memory and Desire in Katherine Burdekin's Swastika Night". Le transformazioni del narrare. Eds. E. Sciliani, A. Cecere, V. Intononti y A. Sportelli. Fasano: Schena, 1995. 293-309. "The Persistence of Hope in Dystopian Science Fiction". PMLA 119, 3 (2004): 518-521.

Bloch, Ernst. The Principle of Hope. Trad. Neville Plaice, Stephen Plaice y Paul Knight. Massachusetts: MIT Press, 1986.

Braun, Lucille V. "Narrative Strategies in La última canción de Manuel Sendero". Revista Canadiense de Estudios Hispánicos 20, 3 (1996): 409-432.

Derrida, Jacques. "How to Avoid Speaking: Denials". Derrida and Negative Theology. Eds. Harold Coward y Toby Foshay. Albany: SUNY Press, 1989. 73-136.

Dorfman, Ariel. La última canción de Manuel Sendero. México D.F.: Siglo XXI, 1982.

Eagleton, Terry. "Utopia and Its Opposites". Socialist Register 36 (2000): 31-40.

Jaque, Claudio. The Noise of Time. Santiago: Createspace: U.S., 2010.

Kim, Euisuk. "Una aproximación psicoanalítica a la obra de Ariel Dorfman". Tesis para optar al grado de Doctor en Filosofía. Minneapolis: University of Minnesota, 2001.

Levitas, Ruth. The Concept of Utopia. Oxfordshire: Peter Lang, 1990. "Educated Hope: Ernst Bloch on Abstract and Concrete Utopia". Utopian Studies 1, 2 (1990): 13-26.

"Pragmatism, Utopia and Anti-Utopia". Critical Horizons. A Journal of Philosophy and Social Theory. 9, 1 (2008): 42-59. 
Mannheim, Karl. Ideology and Utopia. An Introduction to the Sociologyof Knowledge. Trad. Louis Wirth y Edward Shils. Londres: Routledge, 1954.

McClennen, Sophia. Ariel Dorfman: an aesthetics of hope. Durham: Duke University Press, 2010.

Moylan, Tom. Scraps of the Untainted Sky. Science Fiction, Utopia, Dystopia. Boulder: Westview Press, 2000.

Ricoeur, Paul. Lectures on Ideology and Utopia. Nueva York: Columbia University Press, 1986.

Sargent, L.T. "The Three Faces of Utopianism Revisited". Utopian Studies, 5, 1 (1994): 1-37.

"Ideology and Utopia: Karl Mannheim and Paul Ricoeur". Journal of Political Ideologies 13, 3 (2008): 263-273.

Varsam, María. "Concrete Dystopia. Slavery and its Others". Dark Horizons: Science Fiction and the Dystopian Imagination. Londres: Routledge, 2003. 203-224.

Webb, Darren. "Modes of Hoping". History of the Human Sciences 20, 3 (2007): 65-83.

"Exploring the Relationship between Hope and Utopia: Towards a Conceptual Framework". Politics 28, 3 (2008): 197-206. 